\title{
Research on Dynamic Change of Reservoir Porosity Based on Coupled Pore Fluid Flow and Stress Analysis
}

\author{
Jiyong $\mathrm{HAN}^{1,}$, , Dudu MA ${ }^{1, \mathrm{~b}}$, Yafeng $\mathrm{JU}^{2, \mathrm{c}}$, Kai ZHAO ${ }^{1, \mathrm{~d}}$, Yonghua $\mathrm{XU}^{1, \mathrm{e}}$ and \\ Shihui GAO ${ }^{1, \mathrm{f}}$ \\ ${ }^{1}$ Xi'an ShiYou University, Xi'an, China \\ ${ }^{2}$ Oil and Gas Technology Institute of PetroChina ChangQing Oilfield Company, Xi'an, China \\ a306822009@qq.com, b1093618460@qq.com
}

Keywords: Rock mechanics, Seepage mechanics, ABAQUS, Coupled pore fluid flow and stress, Porosity, Bulk strain

Abstract. Due to the challenge of complex problems in petroleum engineering field, the coupled pore fluid flow and stress analysis of reservoir has become a focus of study. Based on the rock mechanics and seepage mechanics theory, the governing equations of the coupled pore fluid flow and stress were given for the injection and production of tight sandstone reservoir. We considered the effect of reservoir temperature and pore pressure changes on the bulk strain of sandstone skeleton,these further affect porosity, a mathematical model has been established for the injection and production of tight sandstone reservoir,which described the dynamic changing of porosity as the variations of reservoir temperature, pore pressure and bulk strain. The numerical simulation results of the coupled pore fluid flow and stress in the injection and production of reservoir better reflects the actual date by using ABAQUS software, which has a significant impact on the oilfield development.

\section{Introduction}

In the process of reservoir injection-production, the injection of liquid through injection well caused the pore pressure increment of reservoir around the injection well, which generated change of bulk strain, and then caused increment of porosity. In the meantime, increased porosity had an effect on the pore fluid flow and distribution of pore pressure. For a production well, vice versa. In addition, due to the injection of normal temperature liquid into the reservoir,lower temperature produced in reservoir, which also generated change of bulk strain, and then caused increase of porosity ${ }^{[1,2,3,4]}$. Based on the classical seepage mechanics, the purpose of this study was to research the law of coupled pore fluid flow and stress in the the injection and production of tight sandstone reservoir, and the change law of porosity with the variations of reservoir temperature, pore pressure and bulk strain, which can make seepage mechanism better fit the actual date.

\section{Governing equations of coupled pore fluid flow and stress}

It is well known that the matrix form of the rock mechanics equilibrium equation and seepage equation were given by Eq. 1 and Eq. 2 respectively:

$$
\begin{aligned}
& {[K]\{\Delta \bar{\delta}\}-[L]\{\Delta \bar{p}\}=\{F\}-\{I\}} \\
& {[\hat{B}]^{T}\{\bar{v}\}+[\hat{H}]\{\bar{p}\}=\{Q\}}
\end{aligned}
$$

And direct coupling equation(Eq. 3) can be derived:

$$
\left\{\begin{array}{l}
{[K]\{\Delta \bar{\delta}\}-[L]\{\Delta \bar{p}\}=\{F\}-\{I\}} \\
-[B]^{T}\{\Delta \bar{\delta}\}-\Delta t[H]\{\Delta \bar{p}\}=\{R\}
\end{array}\right.
$$

where 


$$
\{R\}=\Delta t\left[\{Q\}_{t+\Delta t}+[\hat{B}]^{T}\{\bar{v}\}_{t+\Delta t}+[\hat{H}]^{T}\{\bar{p}\}_{t+\Delta t}\right]
$$

The numerical calculation of Eq. 3 can be caculated by ABAQUS. software.

\section{Porosity dynamic change model of tight sandstone reservoir}

Generally, the deformation of tight sandstone reservoir is small. Based on the theory of small deformation, the shear strains can be ignored, and bulk strain is superposition of linear strain (Eq. 5):

$\varepsilon_{v}=\varepsilon_{1}+\varepsilon_{2}+\varepsilon_{3}$

Building of the porosity dynamic change model.

dynamic change model I.

Based on the continuity equation ${ }^{[5]}$, the continuity equation (Eq. 6) ${ }^{[1]}$ for skeleton of tight sandstone:

$$
\frac{\partial(1-\varphi)}{\partial t}+(1-\varphi) \frac{\partial \varepsilon_{v}}{\partial t}=0
$$

calculating integral of Eq. 6, and ignoring the second order items, we have obtained Eq. 7:

$\varphi=\varphi_{0}+\left(1-\varphi_{0}\right) \Delta \varepsilon_{v}$

The equation 7 shows the dynamic change of porosity with the change of bulk strian increment.

dynamic change model II.

If we only consider that the thermal expansion of skeleton leads to the change of the sandstone volume, based on the definition of porosity and bulk strain,the model II(Eq. 9)can be obtained:

$\Delta V_{r}=V_{r} \gamma\left(T-T_{0}\right)$

$\varphi=\frac{1}{1+\varepsilon_{v}}\left[\varphi_{0}+\varepsilon_{v}-\left(1-\varphi_{0}\right) \gamma\left(T-T_{0}\right)\right]$

The equation 9 is that the porosity dynamic change of reservoir with the changes of bulk strian and temperature.

dynamic change model III.

On the basis of temperature change, pore pressure change, bulk strian change ,a new dynamic change model of reservoir has been established.

Based on the coefficient of compressibility of sandstone ${ }^{[6]}$, the empirical correlation of the porosity with the bulk modulus and skeleton bulk modulus of sandstone ${ }^{[7,8,9]}$, and the relationship between bulk modulus and young's modulus ${ }^{[6]}$, the deformation of skeleton caused by the change of reservoir temperature and pore pressure can be represented as Eq. 10:

$$
\Delta V_{r}=V_{r} \gamma\left(T-T_{0}\right)+V_{r}\left(p-p_{0}\right) c_{r}
$$

based on the definition of porosity and bulk strain,the model III(Eq. 11)can be got:

$$
\varphi=\frac{1}{1+\varepsilon_{v}}\left[\varphi_{0}+\varepsilon_{v}-\left(1-\varphi_{0}\right) \gamma\left(T-T_{0}\right)+\left(p-p_{0}\right) \frac{3(1-2 v)}{(1+50 \varphi) E_{b}}\right]
$$

The equation 11 is that the porosity dynamic change of reservoir with the changes of bulk strian, temperature, and pore pressure.

Optimization of the Porosity dynamic change model. 
Taking an example of the Chang 6 tight sandstone reservoir of a block in ChangQing oilfield, parameters showed in Table 1. By Eq. 11 demonstrated that the pore pressure change has a certain influence on the porosity. Due to the better applicability to the actual conditions, the following study is based on the change model III,simulated the coupled pore fluid flow and stress of the reservoir along the injection and production.

\title{
Numerical simulation research of coupled pore fluid flow and stress of tight sandstone reservoir
}

parameters and boundary conditions.

Using the reverse five-spot flood system ,it's size is $200 \mathrm{~m} \times 200 \mathrm{~m}$. The parameters showed in Table 1.The seepage boundary is closed. The vertical displacement is zero at the bottom of the reservoir.The horizontal displacement is zero around the reservoir boundary. The position of injection well and production wells are fixed, and the top boundary of reservoir is constant stress boundary.

Table 1 Parameters of Chang 6 reservoir in a block of ChangQing oil field.

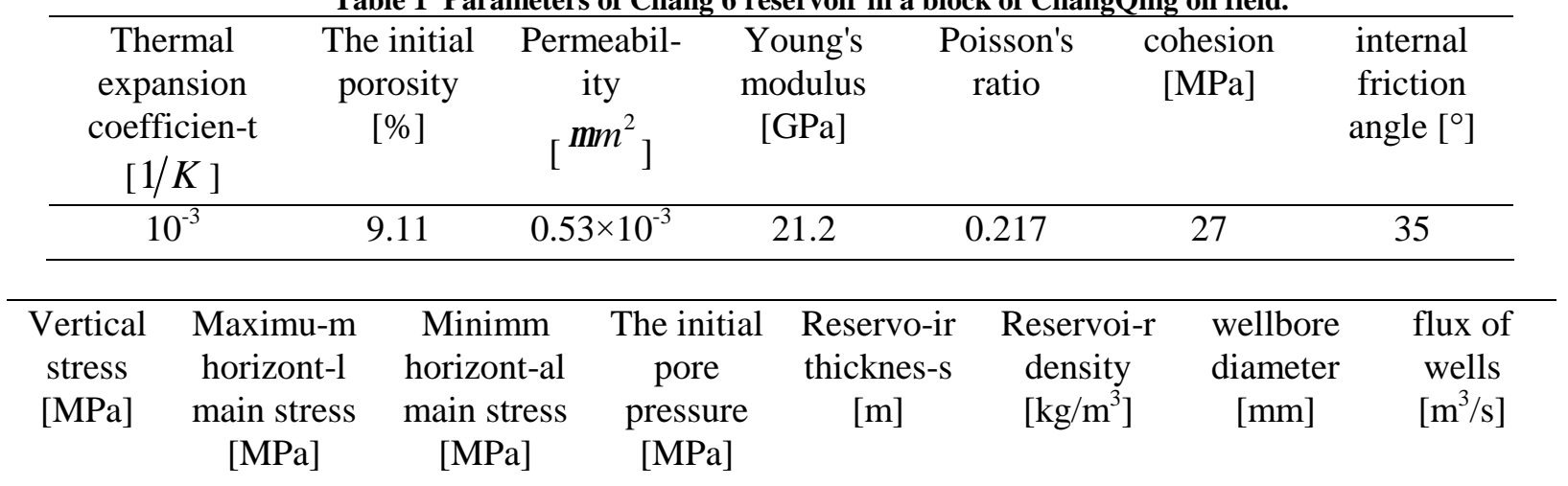

\begin{tabular}{llllllll}
\hline 54.79 & 45.64 & 33.8 & 18 & 10 & 2500 & 400 & 0.001 \\
\hline
\end{tabular}

Numerical simulation result.

The figure 1 showed that the pore pressure increased around injection well ,the sweep area is with radius $81 \mathrm{~m}$; the pore pressure decreased around production well,the sweep area is with radius $44 \mathrm{~m}$, when the injection-production time was 25days. As the injection-production time continued, the sweep area of the pore pressure increment has expanded. The pore pressure around the injection well showed in Table 2,and it is similar to a production well,no more tautology here. Due to the tight sandstone reservoir, injection and production flux is very small, and caused small change of pore pressure, which is close to engineering practice.

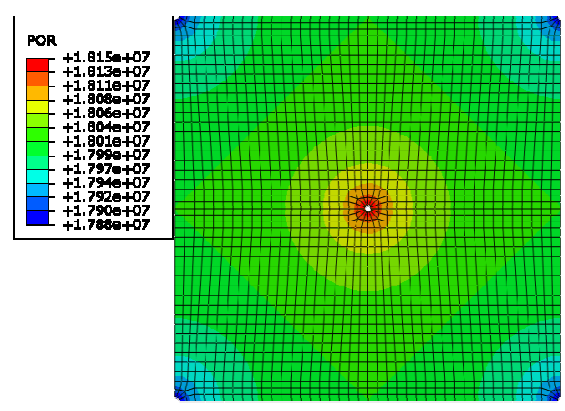

a) $25 \mathrm{~d}$

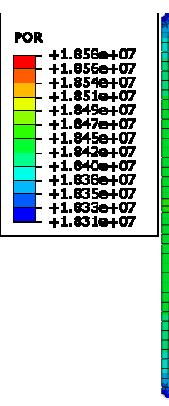

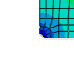

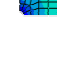

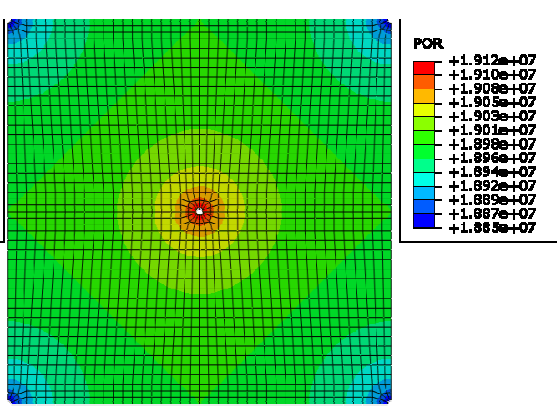

b) $825 d$

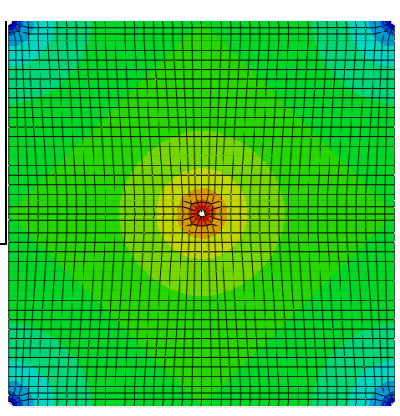

c) $1825 \mathrm{~d}$

Fig. 1 The pore pressure change when injection-production time was $25 \mathrm{~d}, \mathbf{8 2 5 d}$,and $1825 \mathrm{~d}$. 
Table 2 Pore pressure around the injection well

\begin{tabular}{ccccc}
\hline Injection-production time[d] & 0 & 25 & 825 & 1825 \\
\hline Pore pressure[MPa] & 18 (initial pore pressure) & 18.15 & 18.58 & 19.12 \\
\hline
\end{tabular}

The figure 2 showed that the bulk strain when injection-production time was 25 days ,825days, and 1825days, the bulk strain around the injection well showed in Table 3 , and it is similar to a production well. When it was 25days, the pore pressure increased around the injection well, which caused tensile strain , and the porosity increased accordingly ; the pore pressure decreased around the producing well, which caused compressive strain, and the porosity decreased accordingly . As the injection-production time continued, when the time was 1825 days, the porosity around the injection well increased by $0.12 \%$.

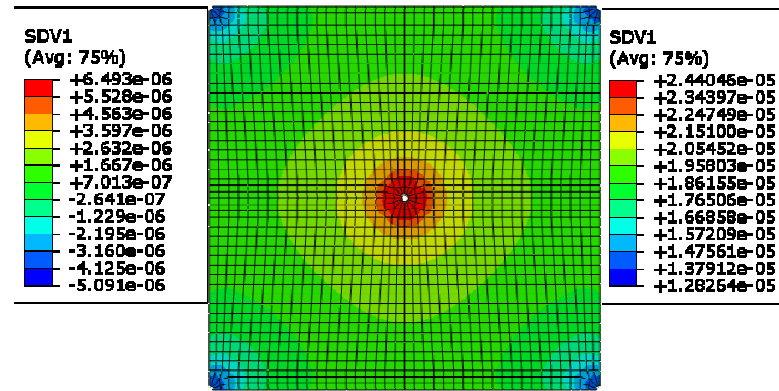

a) $25 \mathrm{~d}$

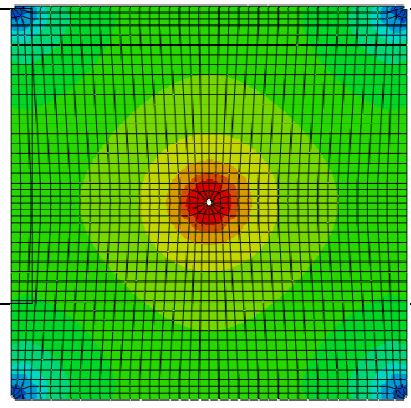

b) $825 \mathrm{~d}$

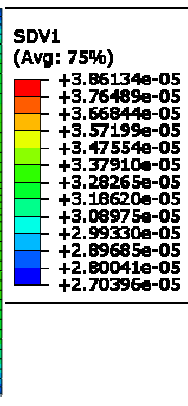

Fig. 2 The bulk strian of tight sandstone when injection-production time was $25 \mathrm{~d}, 825 \mathrm{~d}$, and $1825 \mathrm{~d}$.

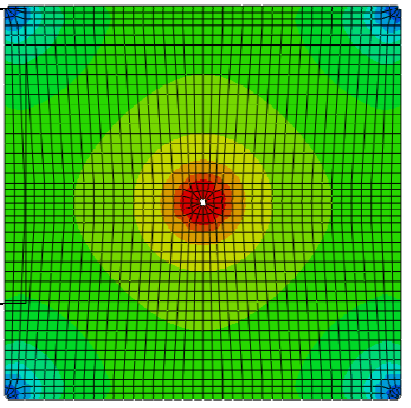

c) $1825 \mathrm{~d}$

Table 3 Bulk strain around injection well

\begin{tabular}{ccccc}
\hline Injection-production time[d] & 0 & 25 & 825 & 1825 \\
\hline Bulk strain & 0 & $6.49 \times 10^{-6}$ & $24.40 \times 10^{-6}$ & $38.61 \times 10^{-6}$ \\
\hline
\end{tabular}

\section{Conclusions}

The numerical simulation shows that the pore pressure change has a certain influence on the porosity, when injection-production time was 1825 days, the pore pressure around injection well increased from $18 \mathrm{MPa}$ to $19.12 \mathrm{MPa}$, which caused bulk strain increasing range from 0 to $38.61 \times 10^{-6}$, and the porosity increased by $0.12 \%$. Pore pressure decreased around producing well, as the time progressed, the pressure of whole reservoir increased. At the beginning of injection-production, generated tensile strain caused the increasing of porosity around injection well, for production well, vice versa. As the time progressed, only generated tensile strain,and the porosity of whole reservoir increased .The numerical simulation of coupled pore fluid flow and stress in the injection-production process of reservoir by ABAQUS. software can guide the oilfield development. 
Table 4 Nomenclature

\begin{tabular}{ccccc}
\hline$\{I\}$ & {$[\hat{B}]$} & $\{\bar{v}\}$ & {$[\hat{H}]$} & $\{\bar{p}\}$ \\
\hline $\begin{array}{c}\text { unbalanced force } \\
\text { in the iterative process }\end{array}$ & $\begin{array}{c}\text { The node } \\
\text { displacement } \\
\text { corresponding } \\
\text { amount of volume } \\
\text { change }\end{array}$ & $\begin{array}{c}\{\Delta \bar{\delta}\} \\
\text { The } \\
\text { time } \\
\text { thative of }\end{array}$ & $\begin{array}{c}\text { Seepage } \\
\text { matrix }\end{array}$ & $\begin{array}{c}\text { Pore } \\
\text { pressure }\end{array}$ \\
\hline
\end{tabular}

\begin{tabular}{cccccc}
\hline$[K]$ & $\{\Delta \bar{\delta}\}$ & {$[L]$} & $\{\Delta \bar{p}\}$ & $\{F\}$ & $\{Q\}$ \\
\hline $\begin{array}{l}\text { Stiffnes- } \\
\text { s matrix }\end{array}$ & $\begin{array}{c}\text { The node } \\
\text { displacement } \\
\text { increment }\end{array}$ & $\begin{array}{c}\text { Pore pressure } \\
\text { corresponding nodes }\end{array}$ & $\begin{array}{c}\text { Pore pressure } \\
\text { increment }\end{array}$ & $\begin{array}{c}\text { he node } \\
\text { loads }\end{array}$ & $\begin{array}{c}\text { The node } \\
\text { flux }\end{array}$ \\
\hline
\end{tabular}

\begin{tabular}{|c|c|c|c|c|c|c|c|c|c|}
\hline$\varphi$ & $\varphi_{0}$ & $p$ & $T-T_{0}$ & $\Delta V_{r}$ & $c_{r}$ & $\gamma$ & $p-p_{0}$ & V & $E_{b}$ \\
\hline $\begin{array}{c}\text { Poro-si } \\
\text { ty }\end{array}$ & $\begin{array}{c}\text { The } \\
\text { initial } \\
\text { porosit-y }\end{array}$ & Pore pressure & $\begin{array}{l}\text { Reserv-oi } \\
\text { r } \\
\text { temper-at } \\
\text { ure } \\
\text { change-s }\end{array}$ & $\begin{array}{c}\text { volume } \\
\text { changeof } \\
\text { Sandston-e } \\
\text { skeleton }\end{array}$ & $\begin{array}{l}\text { Coeffici-en } \\
\text { t of } \\
\text { compres-si } \\
\text { bility of } \\
\text { sandsto-ne }\end{array}$ & $\begin{array}{l}\text { Thermal } \\
\text { expansi-on } \\
\text { coeffici-en } \\
t(1 / \mathrm{k})\end{array}$ & $\begin{array}{c}\text { Pore } \\
\text { pressure } \\
\text { increme-nt }\end{array}$ & $\begin{array}{l}\text { Poisson'-s } \\
\text { ratio }\end{array}$ & $\begin{array}{c}\text { Young's } \\
\text { modulu-s } \\
\text { of } \\
\text { sandsto-ne }\end{array}$ \\
\hline
\end{tabular}

\section{Acknowledgements}

This work was financially supported by National Natural Science Foundation of China (Grant No. 51 604225), " Eleventh Five-Year" Plan key projects supported by National Science and Technology(2 007BAB17B04), Industrial research project of Science and Technology Department of Shanxi Provi nce "key technology research of horizontal wells fracturing of dense reservoir" (2013K11-22) a-nd Scientific research plan projects of Xi'an Education Department(14JK1583).

\section{References}

[1] Zhijun ZHOU. The theory and application research of fluid-solid coupling seepage flow in low permeability reservoir [D].Da Qing: Daqing Petroleum Institute, 2003.“In Chinese”.

[2] Shangping GUO. Seepage mechanics progress [C]. Beijing: Petroleum industry press.1996:1-12.“In Chinese”

[3] Lewis R W, Sukinnan Y. Int.J.Num.Anal.Methods Geomash.1993,17:577—598.

[4]Pingchuan DONG ,Xiaohe XU .OURNAL OF GEOMECHANICS, 1999， 5(3): 17-25.“In Chinese"

[5]Shifeng XUE ,Huizhen SONG . Seismogeology.1999, 21(3): 243-252."In Chinese”

[6]Chunguang LI ,Shuilin WANG ,Hong ZHEN the relationship of Porous medium porosity and bulk modulus [J]. Rock and Soil Mechanics, 2007, 28(2): 293-296."In Chinese"

[7] Guangming ZHANG ,He LIU „Jing ZHANG .Rock Mechanics， 2010，31(5): 1657-1662.“'In Chinese"

[8]Pingchuan DONG ,Xiaohe XU . Journal of oil, 1998,19（1）: 64-70. "In Chinese”

[9]Meihou YUN ,Weiqi YI ,Honyan ZHUANG . Oil geophysical prospecting, 2001, 36(3): 308314."In Chinese" 